\title{
A Survey on the Controller Placement Problem in SDN
}

\author{
Lakshita Agarwal \\ Department of Computer Engineering, G.B.P.U.A.T, Pantnagar, Uttarakhand, India \\ Email: lakshitaa3@gmail.com \\ Chetan Singh Negi \\ Department of Computer Engineering, G.B.P.U.A.T, Pantnagar, Uttarakhand, India \\ Email: csnegi.iitkgp@gmail.com \\ Jalaj Sharma \\ Department of Computer Engineering, G.B.P.U.A.T, Pantnagar, Uttarakhand, India \\ Email: jalajsharma.cse@gbpuat-tech.ac.in \\ Sunita Jalal \\ Department of Computer Engineering, G.B.P.U.A.T, Pantnagar, Uttarakhand, India \\ Email: sunita.jalal@gmail.com
}

\begin{abstract}
Software-defined networking (SDN) is a technology that is emerging in today's world and it is mainly used for changing the state of the network by breaking the older version of it and by separating the network's control layer from the layer of the routers and switches. It also introduces the ability to program any network in any given situation and it is also promoting the logical centralization of the network control. SDN makes it easy to introduce and create new inventions in a networking system, simplifies the network management and makes net- work evolution easier. In SDN, the control plane and the data plane can be separated with the help of a well-defined programming interface between the SDN controllers and the switches. The Controller Placement Problem (CPP) is one of the most important tasks that have to be done in the Software Defined Networks. CPP affects all the desired aspects of a decoupled control plane, for example the option of state distribution, the fault tolerance capacity and also the performance metrics of a network. In latest researches, we will study about the introduction of a novel method named Garter Snake Optimization Capacitated Controller Placement Problem (GSOCCPP) to obtain the near-optimal minimal propagation delays in the Capacitated Controller Placement Problems.
\end{abstract}

Keywords - Software defined network (SDN), Controller Placement Problem (CPP), Pareto-Optimal Controller Placement (POCO), GSOCCPP, Capacitated Controller Placement Problems (CCPP).

\section{INTRODUCTION}

The Internet has created a digital society, where almost everything is connected to each other and is accessible from anywhere in the world. Networking has always been very traditional, and is known to be the traditional networking. There are specific devices like the routers, switches, and firewalls that are used for different specific tasks inside any given network.

Despite the widespread of networking, traditional IP networks are quite complex and very hard to manage. Current networks are also vertically integrated, i.e., the control plane and data planes are kept together, which makes the network configuration more difficult.

Software-defined networking (SDN) is a technology that is emerging in today's world and it is mainly used for changing the state of the network by breaking the older version of it and by separating the network's control layer from the layer of the routers and switches. SDN also promotes the logical centralization of the network control, and introduces the ability to program any given network [1].

SDN is the latest and the most commonly used buzzword in field of Information Technology, which is getting more popular every year. SDN makes it easier to introduce and create new inventions in networking, simplifying the network management and easier network evolution.

In SDN, the separation between the control and data plane can be done with the help of a programming interface which is well-defined and lies between the SDN controllers and the SDN switches.

With the help of the well-defined application programming interface (API), the controller has the direct control over the state in the data plane elements [2].

Software Defined Network's architecture helps to decouple the forwarding functions and the network control, that further enables the network control to become a directly programmable function and also it helps in abstracting the underlying infrastructure from the applications and from the network services.

\subsection{Traditional Network Vs Software Defined} Networks:

Traditional network is referred to as a conventional technique of networking that can use fixed hardware 
devices, like, the router or a switch for controlling the traffic on the network.

Software Defined Networks is also a networking approach that uses software applications to enable the management and control of the network system. It uses network virtualization for improving the performance of the network.

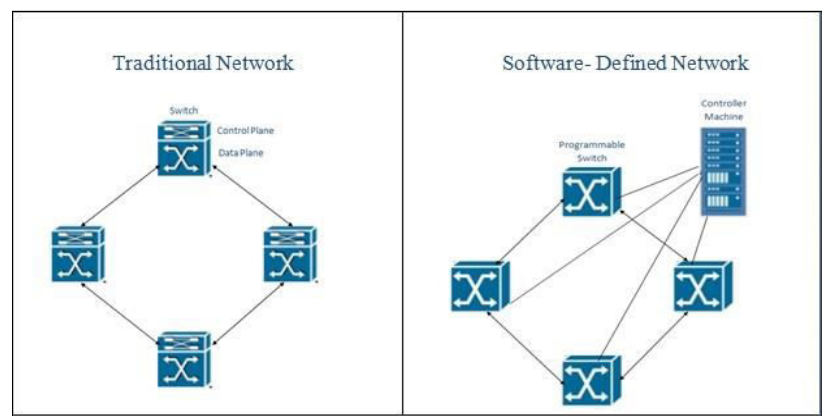

Fig. 1. Traditional Network VS SDNs.

TABLE 1. Difference between Traditional Networks and SDNs

\begin{tabular}{|c|c|}
\hline $\begin{array}{l}\text { Traditional } \\
\text { Networks }\end{array}$ & $\begin{array}{c}\text { Software-Defined } \\
\text { Networks }\end{array}$ \\
\hline $\begin{array}{l}\text { - It is a conventional } \\
\text { approach for } \\
\text { networking. } \\
\text { - It is a distributed } \\
\text { control method. } \\
\text { - Traditional networks } \\
\text { are non-programmable. } \\
\text { - Traditional networks } \\
\text { have closed interface. } \\
\text { - Control plane and data } \\
\text { plane are in same } \\
\text { plane. } \\
\text { - Consists of static and } \\
\text { manual configurations. } \\
\text { - No prioritization takes } \\
\text { place in the network. } \\
\text { - Difficult to reprogram } \\
\text { the existing program. } \\
\text { - It is higher in cost as } \\
\text { compared to SDNs. } \\
\text { - They are complex in } \\
\text { terms of the structure. } \\
\text { - Maintenance cost is } \\
\text { quite high. } \\
\text { - In traditional } \\
\text { networks, extensibility } \\
\text { is very low. }\end{array}$ & $\begin{array}{l}\text { - It is a virtual approach } \\
\text { for networking. } \\
\text { - It is a centralized } \\
\text { control method. } \\
\text { - SDNs are } \\
\text { programmable. } \\
\text { - SDNs have open } \\
\text { interface. } \\
\text { - Both planes are } \\
\text { decoupled by using } \\
\text { software. } \\
\text { - It is automatic and } \\
\text { takes lesser } \\
\text { configuration time. } \\
\text { - Can prioritize any } \\
\text { packet inside the } \\
\text { network block. } \\
\text { - Easy to reprogram as } \\
\text { needed by the user. } \\
\text { - The cost of SDNs is } \\
\text { not very high. } \\
\text { - SDNs have fewer } \\
\text { complex structures. } \\
\text { - Easy to maintain and } \\
\text { has less maintenance } \\
\text { cost. } \\
\text { - In SDNs, extensibility } \\
\text { is quite high. }\end{array}$ \\
\hline
\end{tabular}

\section{ARCHITECTURE OF SDN}

Software Defined Networks can also provide a global view of the network by the logical centralization of the 'Network Brain'. After the introduction of Software Defined Networks, the data plane inside the network became highly efficient and the programmable packets forwarding devices got represented by a single entity, which is known as the 'Controller' or the 'Network Operating System (NOS)' [2]. Here we can conclude by the architecture of the Software Defined Network, that the control plane and data plane are being separated out.

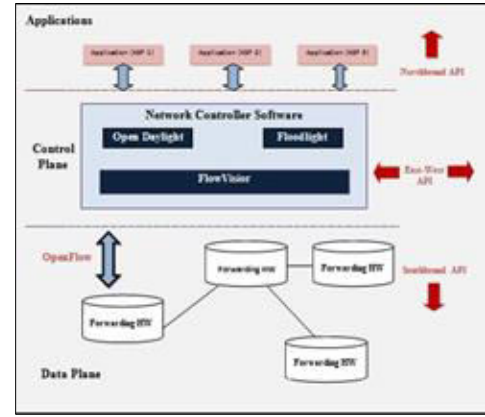

Fig. 2. SDN Architecture.

\section{CONTROLLER PLACEMENT PROBLEM}

As we have seen the architecture of the SDN, here, the main problem that arises is the placement of the controller inside the network. Hence, the Controller Placement Problem (CPP) came into existence. CPP is one of the important tasks that take place inside the Software Defined Networks. There is a need to assign switches to the controllers inside the network. This is necessary to provide the Quality of Service inside the network [3]. With the history of the computer networking, we have studied that the control plane of the network works with the help of packet networks, which have been tightly coupled to the data plane.

These planes decide how and where to forward the packet inside the network, with the process called the packet forwarding. The controller placement problem needs to be solved because it affects the functions of the decoupled control plane, as well as it also affects the state distribution options inside the network. Because of the controller placement problem the fault tolerance and the performance metrics of the network also gets affected.

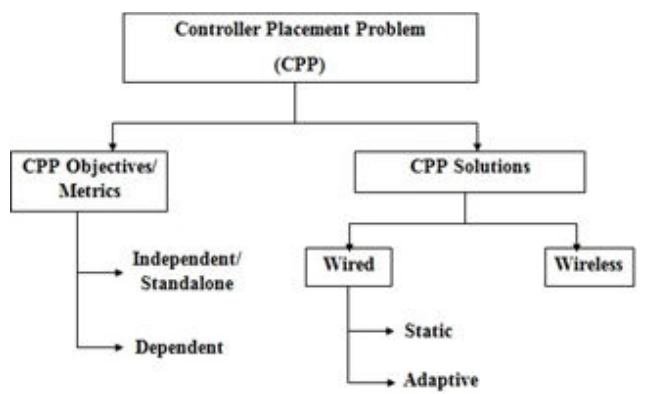

Fig. 3. Controller Placement Problem

The controller placement problem is mainly threefold in nature, and indicates:

a. The number of controllers that should be placed inside a given network,

b. The locations at which these controllers are to be placed, and

c. The function that are assigned for providing the switches to the controllers and to design an efficient and accurate control plane inside the network. 
In Software Defined Networks (SDNs), placing the controller inside the net- work is the most important task to perform. For placement of the controllers inside the network, there have been many researchers working since a very long time. Now we will further elaborate the research work that is done in this field [4] [5].

\section{DIFFERENT APPROACHES USED FOR SOLVING THE CONTROLLER PLACEMENT PROBLEM}

According to [6], B. Heller, R. Sherwood and N. McKeown, were the first researchers who stated the problem of the controller placement problem, in the year 2012. In their research work they focused mainly on the two questions:

1. How many controllers are needed in the network? and

2. Where should the controllers go?

With their research, they concluded that, one controller location is often sufficient to meet the time requirements inside the network. And also, they stated that 'where' and 'how many' controllers should be placed, is purely dependent on the reaction bound desired, choice of the metrics used and the topology of the network considered [7].

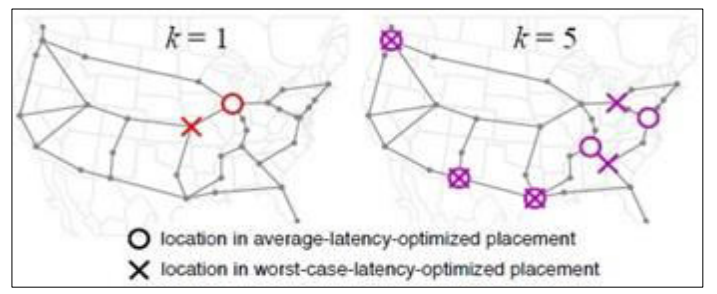

Fig. 4. How does placement affects latency in Internet2 OS3E deployment [6].

There appeared no proper placement rule that can be applied to any networkfor placing the controllers. They concluded that, wherever the user wished to add the controllers, they could use the methods and can determine their own best controller placements.

\subsection{Reliability in SDN Control Network:}

In May 2013 [8], researchers Y. Hu, et al., worked on the placement of the controllers in the software defined network, so that the reliability of the control network gets maximized. Several placement algorithms were developed, after presenting a metric that characterized the feature of reliability in the SDN control network. In real topologies, there were the following benefits that were observed by using different algorithms:

1) The performance of the placement was dependent on the specific algorithmused,

2) The process of simulated annealing provided the best solution that wereoptimal,

3) The number of controllers that are being used must be chosen properly,

4) The reduction of reliability occurs when we place too many or few controllers inside the network,

5) Tradeoffs between metrics appeared in the simulation results,

6) The corresponding latencies were sufficient to meet existing response time requirements, when optimization for reliability was done inside the network.

\subsection{Pareto-Optimal Controller Placement:}

In further researches, researchers D. Hock, et al., [9], introduced one of the most important aspects for the controller placement problem. It included different types of resilience and failure tolerance techniques which were known as the "Pareto-Optimal Controller Placement (POCO)".

This technique provided the placement of the controllers by the operator of a network to be Paretooptimal. They revealed in there finding, that in most of the topologies that should be used, there must be more than 20 percent of all the nodes that should the controllers.

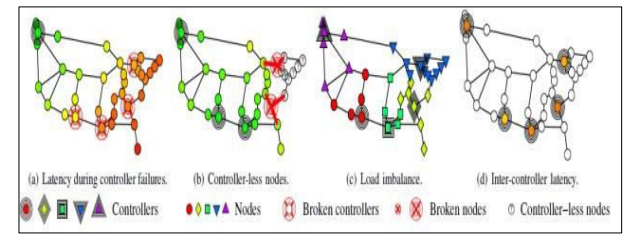

Fig. 5. Illustration of different issues that needs to be considered when opting the resilience of the controller placement [9].

Further, using this assumption, they also asked to assure that there must be continuous connections of all nodes to one of the controllers for any scenarios in case of a node's failure or for arbitrary double link. For POCO framework, a range of options to select the placement that is most adequate for their particular needs, were offered by the authors in the network operators. To validate these findings, the evaluations on a large set of 146 topologies from the Topology Zoo were performed.

\subsection{Introduction to the Cascading Failures of the Controllers:}

In the next approaches, reliability of the control network became an important aspect in the controller placement problem, but there are few threats that were engaged in it. In October 2013, the researchers, Guang Yao, Jun Bi and Luyi Guo, worked on one of the potential threats to reliability of software defined networking (SDN). The threat was introduced as the 'Cascading Failures of the Controllers' [10].

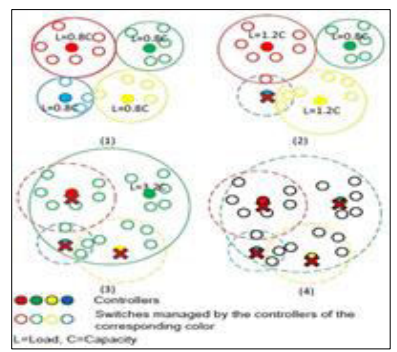

Fig. 6. Cascading Failures in the SDN network [10]. 
It was also concluded that when the initial failed controller carried maximum load, cascading failure with high probability can make the whole SDN network collapse [11]. Also, if we implement some strategies, like, initial load balance strategy, that ensures controller load, tolerance parameters and load distribution, we can prevent the cascading failures effectively.

\subsection{Formation of K-Critical Algorithm:}

After this, researchers, Y. Jimenez, C. Cervello-Pastor and A. J. Garcia, defined the principles for desired control layer characteristics that optimized the management of the network designing and designed a scalable control layer for distributed SDN [12].

For the purpose of designing the network, they evaluated and improved the previous approaches and algorithms like the K-Critical Algorithm.

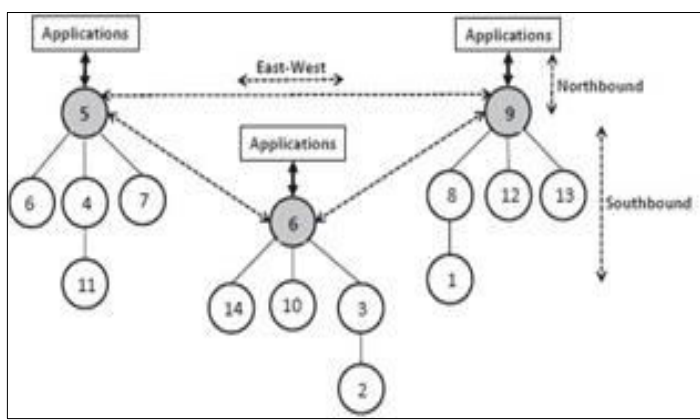

Fig. 7. Representation of control layer in the NSFNet Topology [12].

They concluded that, the network operations can be affected by the poor controller selection and which further affects control network robustness. As the delay improvement is almost negligible, using more than the desired number of controllers can lead to inefficiency of the system as well as can be much costlier. In this problem, the k-Critical algorithm selects the controllers by constructing the robust control layer in the network and then it helps in a better controller selection at the best controller position. In addition, a mechanism that can improve the load migration among the controllers must be defined.

\subsection{Capacitated Controller Placement Problem:}

Now, after the introduction of the K-critical algorithm, a new term was coined for the controller placement problem, which was known as the 'Capacitated Controller Placement Problem (CCPP)'. It was introduced by researchers, Guang Yao, et al., in August, 2014 [13]. This problem considered the load of the controller in the network and then introduced an efficient algorithm to solve it.

The approach showed that this new strategy was able to reduce the maximum number of required controllers and was more efficient. It was further also concluded that, this approach was able to reduce the load that was placed on the maximum load controller. As well as, it can reduce the radius stretch between the $\mathrm{J}$-Center strategy and the Dynamic Scheduling (or Dynamic Controller Provision).

This work was the first one to talk about the factors of the load in the controller placement and the authors defined this problem formally and also introduced efficient algorithms to solve it, by introducing the new strategies like, by increasing the capacity of the control plane [14].

They also introduced less radius-radius stretch in it which consequently reduced the number of controllers and also reduced the load of busiest controllers.

TABLE 2. Comparison between Pareto-Optimal Controller Placement (POCO) and Capacitated Controller Placement Problem (CCPP).

\begin{tabular}{|c|c|}
\hline & \\
\hline $\begin{array}{l}\text { Resilient optimal } \\
\text { solution used in } \\
\text { MATLAB } \\
\text { framework. } \\
\text { It focuses on the } \\
\text { quality of network. } \\
\text { - Works for the } \\
\text { maximum latency. } \\
\text { Minimum } 20 \text { percent } \\
\text { of nodes must be } \\
\text { controllers. } \\
\text { - Provided maximum } \\
\text { latency and fault } \\
\text { tolerance. } \\
\text { Provided maximum } \\
\text { numbers of nodes } \\
\text { required. }\end{array}$ & $\begin{array}{l}\text { - An efficient solution } \\
\text { for load of } \\
\text { controllers. } \\
\text { - Solves the problems } \\
\text { of over load on the } \\
\text { controllers. } \\
\text { - Lesser number of } \\
\text { controllers is } \\
\text { required. } \\
\text { - Radius stretch } \\
\text { between the nodes } \\
\text { was reduced. } \\
\text { - Increased the } \\
\text { capacity of control } \\
\text { plane. } \\
\text { K-center algorithm } \\
\text { was used for } \\
\text { comparison. }\end{array}$ \\
\hline
\end{tabular}

\subsection{Heuristic Approach for CPP:}

After the capacitated controller placement problem (CCPP), a new approach came into existence. This approach was used in the large scale SDN networks. It was a heuristic approach for the controller placement problem and was defined by Stanislay Lange et al. in 2015 [15].

With the help of the heuristic approach, the POCO toolset was extended to less accuracy, but it was able to obtain a faster timing for computation. This approach was performed on a huge collection of real topologies from the Internet Topology Zoo.

In the control plane, metrics that were used in this approach were:

- latency

- resilience against nodes

- link failures

- fault tolerance, and

- load balancing. 


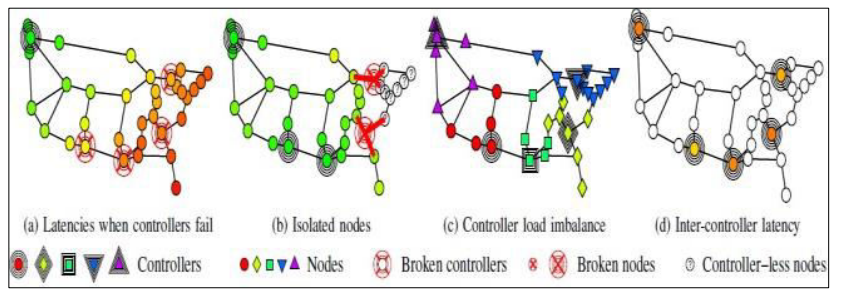

Fig. 8. Accessing the controller placement quality with different measures of objective [15].

These approaches also lead to some of the benefits like:

1) These approaches allowed the analysis of very large problem instances, in an exhaustive manner,

2) In the case of time constraints, for a highly dynamic environment, this approach allowed the trade-off between the accuracy and time of the communication.

3) Such approaches were also used in tackling similar problems that appeared in the context of Network Functions Virtualization (NFV).

\subsection{Multi-controller placement optimization in SDN-based WAN approach:}

Later, the case of multi-controller placement optimization in SDN- based WAN approach was being introduced [16]. In April 2015, researchers, Eugen Borcoci et al, introduced multi- controller implementation approach for large network environment that was able to solve the issues of scalability and reliability of the centralized logical control principles of the SDN.

The main aim of this work was to find an optimal solution for the given criterions and also to achieve optimization in the controller placement, by applying the Multi-Criteria Decision Algorithm (MCDA) in any network. The overall goal was to optimize the overall control plane performance. This method of MCDA was generic enough to be implemented in any kind of scenarios and to achieve overall optimization.

\subsection{Specialized Heuristic Approach for CPP:}

After the heuristic approach, a specialized heuristic approach for solving the controller placement problem was introduced in the large-scale Software Defined Networks by researchers Stanislav Lange, et al., in September 2015 [17]. This work was based upon the specialized heuristics approach, which took into the account a particular set of optimization objectives and returned the solutions that represented the tradeoffs between them.

This approach was employed by automatic decision systems in dynamic environment, because of the low computational time and acceptable margin of errors. This work discussed mainly about:

- Facility location problem,

- Controller placement in Software Defined Networks,

- Use cases that were used for the facility location problem in terms of Software Defined
Networks and Network Functions

Virtualization (NFV) [18].

- Multi-criteria optimization algorithms [19].

This approach was evaluated over 60 real world network topologies and the efforts for developing this specialized approach paid off well. This approach resulted in higher optimization accuracy over the generic heuristic approach.

TABLE 3. Difference between Heuristic Approach and Specialized Heuristic Approach for Controller Placement Problem

\begin{tabular}{|l|l|}
\hline Heuristic Approach & $\begin{array}{c}\text { Specialized Heuristic } \\
\text { Approach }\end{array}$ \\
\hline - POCO toolset was & - Automatic Detection \\
used with respect to & System was used. \\
the performance & - Set of optimizing \\
metrics. & objectives were \\
- Faster time of & detected. \\
computation, lesser & Dynamic \\
accuracy. & environment was \\
Quantification of & used for its \\
errors took place. & working. \\
- Results were trade- & - Results were \\
offs between time and & trade-offs between \\
accuracy. & set of objectives. \\
- Metrics used the & - Facility location \\
latency, resilience, & problem (FLP). \\
link failure, load & - Use cases for FLP \\
balancing. & inside NFV and \\
- Large problem & SDN were solved. \\
instances were & - Provides guiding \\
solved. & algorithms for \\
- Used in highly & quantification. \\
dynamic environment. & - Used as generic \\
- Can solve the & heuristic approach. \\
problems of NFV as & - More accuracy and \\
well. & guaranteed solutions \\
Provides faster & values. \\
yielding time and & \\
less accuracy. & \\
\hline
\end{tabular}

\subsection{Dynamic Controller Placement:}

As studied in earlier works, a term called the 'dynamic controller placement' was been introduced. Researchers Md Tanvir Ishtaique ul Huquey, et al. [20], revisited the controller placement problem and worked on the dynamic controller placement. This problem consisted of the following issues:

1) How to determine the locations of the controller modules that can be bounded for communication latencies,

2) How to find the number of controllers needed per modules for supporting the load on the controller.

The researchers proposed, a solution named LiDy, which was used for combining the controller placement algorithms with dynamic flow management algorithms. 
They evaluated the latencies and controller utilizations of LiDy on the dense and sparse regions inside the network. As the result was formulated, it was observed that a higher utilization was achieved by LiDy when compared to any of the most recent controller placement solutions.

LiDy consisted of the following features:

- Controller modules,

- Unconstrained location search, and

- Dynamic traffic load

LiDy also considered the two algorithms:

1. 'The independent controller module placement algorithm', and

2. 'The dynamic flow management algorithm'. In this work, the final result that was coined was:

a. LiDy offered a combined solution of SDN, i.e., the controller placement problem and the controller scheduling problem.

b. The location of the switches and the required latency constraints were the two main inputs that were being considered in the algorithm.

c. The number of active controllers and the locations of the controller modules were the obtained outputs.

d. Only the first output was static, rests all were dynamic.

e. LiDy achieved higher utilization and similar latency in the most recent solution of the CPP.

\subsection{Multi-Criteria based Optimization of Placement for SDN controllers and forwarding nodes:}

In the context of large networks, the placement of SDN forwarders and controllers was still a big issue that was needed to be solved. In February 2016, researchers, Eugen Borcoci, Tudor Ambarus, Marius Vochin extended the approach of Multi-Controller Optimization in SDN- based WANs (2015) [21], by constructing a software simulation model.

Multi- criteria decision algorithms were presented to provide valuable solutions. Earlier approach was based on the 'multi- criteria optimization algorithm' [22] but this approach mainly focused on the 'multi-criteria decision algorithm' to optimally select solutions based on weighted criteria, for WAN-SDN amongst several controller placement solutions. This approach was able to produce a tradeoff (optimum) result, and also considered several criteria. The method proposed was general and could be applied in various scenarios, so that it achieves an overall optimization in the network. Also, forwarder-controller mapping optimization and backup controller selection were also considered.

\subsection{CPP to enhance performance in Multi-domain SDN Networks:}

In further work, authors Hidenobu Aoki and Norihiko Shinomiya, discussed and formulated the controller placement problem in the multi-domain networks based on the partitioning of the network [23]. This work formulated the controller placement problem based on the network partitioning by using the existing metrics [24]. For a controller location in each domain, this work was considered to be an optimization problem for finding an appropriate node, where a given evaluation functions could be optimized easily.

This algorithm consists of two phases:

1. First phase: the partitioning of a network, and

2. To find the exact locations of the controllers inside the individually partitioned networks, so that it can easily satisfy the metrics of the network.

Therefore, this work defined all the metrics that needs to be considered for the controller placement, for example, the controller-switch latency, the survivability, etc.

\subsection{Reliability Based Controller Placement Algorithm in SDN:}

In June 2016, authors, Jiang Liu Juan Liu, and Renchao Xie introduced the reliability-based controller placement algorithm in SDN [25]. They firstly considered the optimization problem for controller placement under the assumption that there exists the shortest path between the controller and the switches, and then proposing the two most important algorithms:

1. The Clustering based optimal controller placement algorithm, and

2. Sub-optimal algorithm which was based on the greedy algorithms.

After proposing these algorithms, they further extended the controller placement problem to more specific cases using the concept of multi-paths between the controllers and the switches. Further, a modified clustering-based algorithm for optimal solution and greedy based algorithms for sub-optimal solutions were being proposed [26].

The simulation results were observed and it was coined that the performanceof the proposed algorithms was better than the already introduced regular placement strategies.

It was also concluded that the performance of the global clustering algorithm was better than the local greedy algorithm (both the algorithms were not affected with the number of controllers) and the reliability of multi-paths between two nodes was affected by other factors, like: a) the number of paths, b) the path correlation and c) the length of path (only one factor).

\subsection{A K-Self Adaptive SDN controller placement for WAN:}

Existing works showed that there was a need of multiple controllers in WANs with each of them covering at least one small SDN domain. However, the problems of controller placement and SDN domain partition needed to be further addressed. 


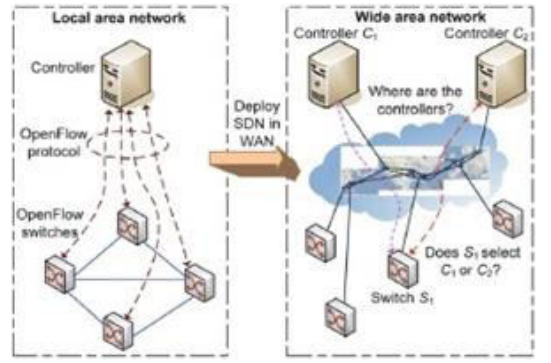

Fig. 9. Controller placement problem in the Wide Area Network (WAN) [27].

So, a new work was proposed that considered the partition of networks using the spectral clustering and included the placement algorithms. A ' $\mathrm{K}$ self-adaptive Software Defined Networks controller placement for WANs' was developed by Peng XIAO, et al., in July 2016 [27]. In their algorithms, the solvable matrix perturbation theory and Eigen-gap were being used. The formulation of a new experimental framework along with the Internet 2 topology and other WAN topologies took place. This was done to evaluate the algorithms. The main idea was to use linear algebra and matrix theory for studying the properties of the similarity matrix and the Laplacian matrix.

To achieve the partition objective, the $\mathrm{K}$ self-adaptive method was proposed which further decided the optimal number of SDN domains. Lastly, the whole placement algorithm was described on the basis of the spectral theory [28]. Experimental results showed that self-adaptive placement was good at solving the SDN controller placement problem and for determining the number of SDN domains. The placement of the controller was more likely a complex function of the topology, metric, and also for finding the value of $K$. This approach presented by the researchers was just a first step towards the SDN domain partition.

\subsection{Density Cluster based Approach for CPP in large-scale SDNs:}

In October 2016, researchers, Jianxin Liao, et al. proposed an approach named as the Density Based Controller Placement (DBCP) [29]. This approach was used for splitting the network into several sub-networks using a density-based switch clustering algorithm [30].

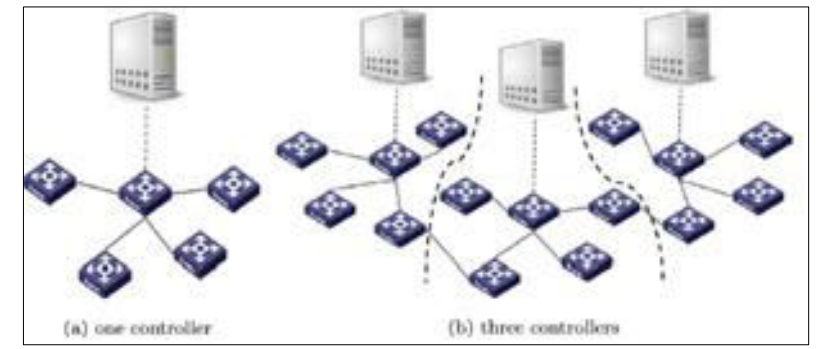

Fig. 10. Example of controller placement in star topologies with switch clustering [30].

In this approach, the major factor for deciding the size of each sub-network was done by evaluating the capacity of the controllers that were being deployed. Further, with the help of the density-based clustering, the optimal number of controllers was obtained. The authors evaluated the performance of this approach on a set of 262 publicly available network topologies which resulted that DBCP provided a better performance than any other approach, when evaluated in terms of the consumption of time taken, propagation latency and fault tolerance.

\subsection{CPP on using SDN in 5G networks:}

In $5 \mathrm{G}$ network, the software defined networks needed to get integrated with the help functions of the Evolved Packet Core (EPC) for the separation of control plane and user data plane. This separation mainly functioned at the Serving GateWay (SGW) and Packet data GateWay [31].

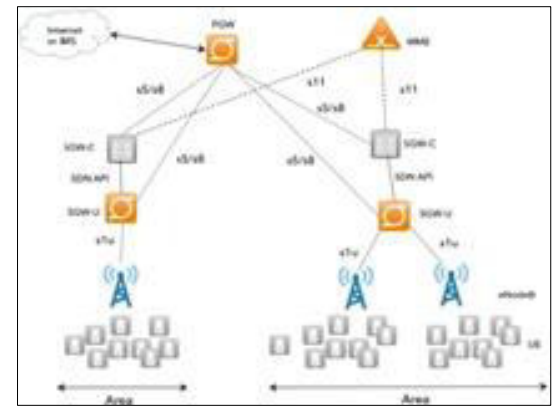

Fig. 11. Mobile Network Architecture based on SDN [31].

These functions resulted in two new entities:

1. The S/PGW-C- integrates all the control plane functions.

2. S/PGW-U-contains only forwarding functions.

In this work, the researchers focused on the problem of the SGW-C placement. Keeping the MME entities unchanged, the researchers mainly focused particularly on the separation between the data plane and control plane functions. This separation was done within the SGW and PGW entities [32]. Furthermore, this separation represented a step forward to $5 \mathrm{G}$ and it introduced several challenges, like:

- There was a need for specifications that defined and specified the interfaces between the GW-C and the GW-U.

- GW-C has to be placed at optimal points in the underlying cloud.

The researchers formulated this problem using optimization models, and a fair solution (i.e., Pareto optimal) was derived using Nash Bargaining game and the threat point. The simulation results showed the ability of the Game Theory based approach to derive a solution that enforced the trade-offs.

\section{INTRODUCTION TO THE CONTROLLER SELECTION PROBLEM:}

After so many research works that we have studied till now, Controller Placement Problem CPP is one of the most important concern in the SDN architecture. 


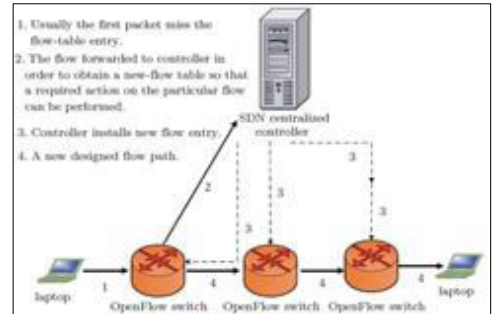

Fig. 12. Basic flow of works in SDN [33].

But till now, we have also found out that there is no strict placement rule that fits best in the SDN network. Therefore, in further works, the researchers tried to transform the controller placement problem (CPP) into the controller selection problem (CSP) [33].

In the dynamic SDN environment, researchers need to study about the issue of CSP but there are a lot of advantages of CSP over the CPP.

CSP can answer about the issues regarding the performance of the control plane, i.e., it can answer the minimum number of controllers that are needed, how to meet the strict and application-specific QoS constraints, the workload distribution of controllers and furthermore, the placement of the controllers.

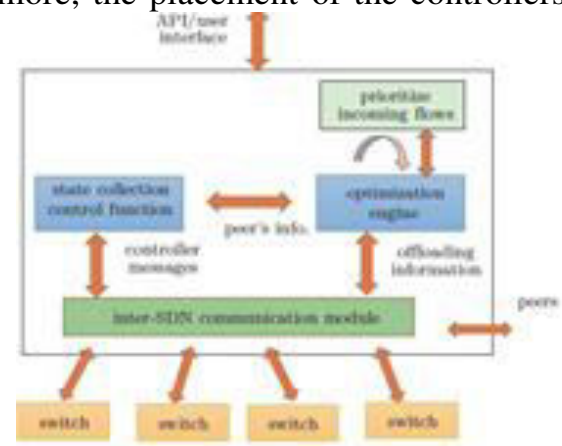

Fig. 13. Proposed flow-based routing module for SDN Controller [33].

Authors showed that when the flow setup was reactively performed, the response time of a controller and the load level affected the controller's performance. They proposed a topology independent framework that investigated the placement/location of the controllers and optimized the control layer as well asit is also used for calculating the number of controllers that are optimal and can be useful for reducing the workload of the network.

The main aim was to motivate the use of Controller Selection Problem, and not for determining any other optimal solution for the placement of controllers inside the network.

Since, the current investigation was based on classical queuing models. Therefore, in this research work, the authors proposed that the CPP could be transformed into a CSP.

\section{RECENT SURVEYS AND APPROACHES THAT HAVE BEEN DONE AND USED:}

\subsection{Multi-controller based SDN approach:}

In March 2018, a survey was conducted by Tao $\mathrm{Hu}$, et al., which was based on the multi-controller based SDN [34]. Investigation for the overview of multi-controllers and the challenges faced by those multi- controllers was performed.

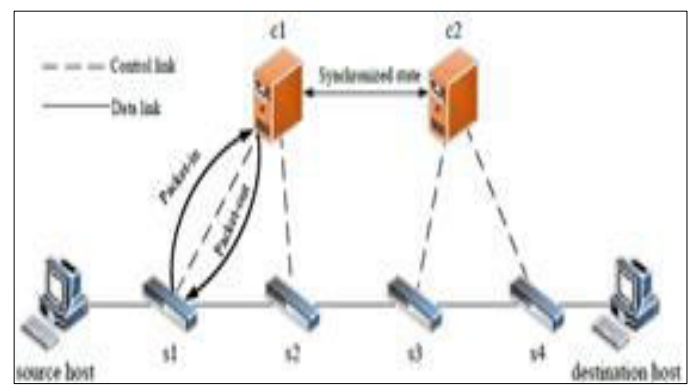

Fig. 14. Working of Multi-controllers [34].

This research was mainly classified into four aspects like:

- Scalability,

- Consistency,

- Reliability and

- Load-balancing.

These aspects purely depended on the process of how the multi-controllers are being implemented and at the end. The authors proposed some of the relevant issues that were related to deal within this research [35].

They investigated the origin of the multi-controllers and also introduced two basic architectures:

1. Flat Design- It was a network that was structured into several domains, where each domain was controlled by a controller situated within its own local network view.

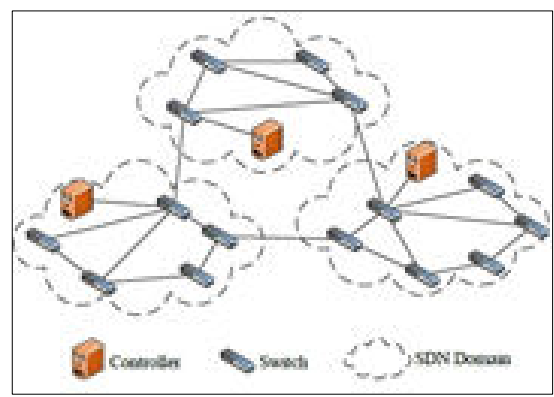

Fig. 15. Flat Design [34].

2. Hierarchical Design: two-layer controllers were used in this architecture, which were:

a. Root controllers: that managed domain controllers and maintained the global network view, and

b. Domain controller: that managed the switches in the local domains, and runs local control applications. 


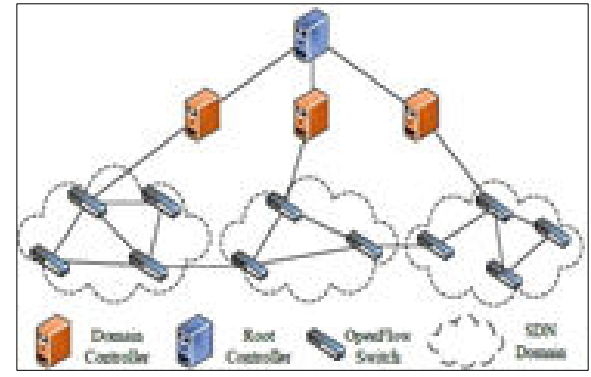

Fig. 16. Hierarchical Design [34].

At the end, they also introduced major research problems that were needed to be considered to implement these multi-controller approaches in the realworld scenarios. This approach uses the switchmigration procedure for controller placement.

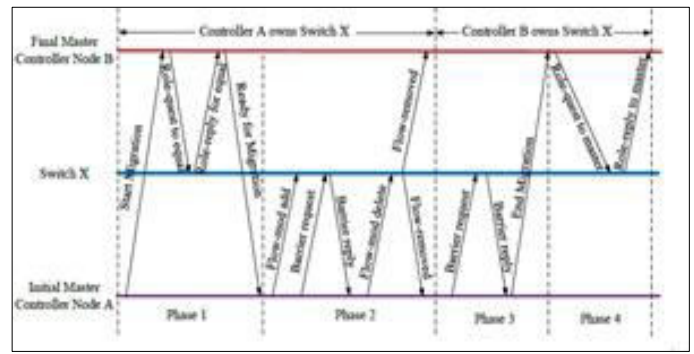

Fig. 17. Switch Migration Process [34].

The main idea for switch migration is to change the relationship between the controllers and switches, dynamically. This process migrates the switches inside the network from the overloading controllers to the under loaded controllers.

\subsection{Research based on the fault tolerance controller} placement in distributed SDN Environment:

As we are already familiar with the term 'fault tolerance' in the CPP of SDN, soin the year 2018 [36], few researchers namely, Adel Alshamrani, et al. worked on the fault tolerance controller placement in distributed SDN environments.

They used approach mainly to optimize the fault tolerance rather than affecting the performances of the controllers. For a smaller number of controllers, the fault tolerance was not worth to be optimized over the latency of the metrics. When the number of controllers was increased, there was a need to optimize the controllers for fault tolerance. But the issue that aroused was whether the faulttolerance metrics continue to increase as the number of controllers increased or not.

\subsection{Approach regarding the optimal and dynamic SDN Controller Placement:}

We already know that several studies promoted using the multiple controllers inside the system of networks. They also limited the use of placing one controller in a large-scale Software Defined Network. The latency, network load and connectivity of the system, are some of the main reasons behind the placement of the controllers. To end such problems, the researchers
Nadia, et al. worked to solve the CPP and dealt with the network load by using an algorithm, called the 'dynamic switch migration algorithm' [37].

The performance analysis and validation of this algorithm showed that the proposed topologies were stable to use and the load balancing occurrences that were presented were being reduced efficiently.

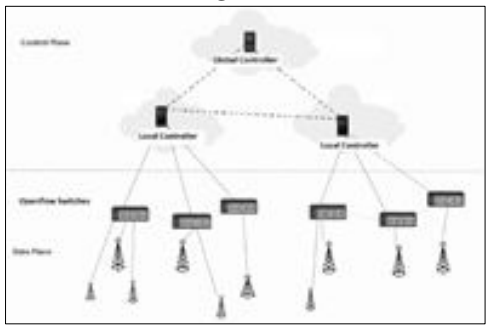

Fig. 18. 5G SDN-based Architecture [37].

An algorithm for solving the controller placement problem was being de- signed. This algorithm used the quadratic program that provided the following output:

1. The locations of the controllers to be placed, and

2. The number of switches to be placed in each domain of the network.

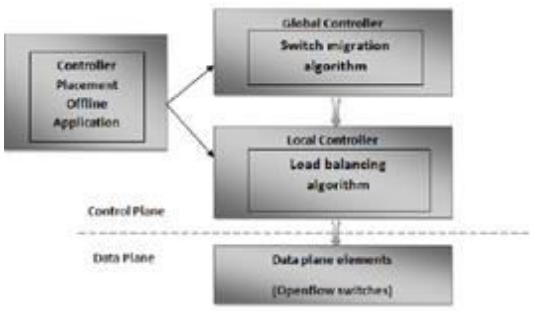

Fig. 19. Integration of proposed algorithm [37].

Furthermore, they developed an algorithm for dynamically migrating switchesin the case of controller overload for preventing the congestions inside the network. The researcher used a local controller application for the purpose of load balancing and a switch migration application for the global controller, during the implementation. On considering the performance analysis, this proposal was much better than the other literature algorithms in terms of network stability. And it was also useful to minimize the number of controller's overloads and also to minimize the probability of overloads occurrences.

\subsection{Controller Placement in Scalable SDN Environment:}

In 2018, Smitha Vinod and X. Agnise Kala Rani [38], discussed various issues that were faced when the controllers are placed in SDN networks. By taking into consideration, many test cases were tried, that were used to obtain a fair solution that were based on different conditions and circumstances. In scalable SDN networks, there is no permanent all-time solution that is available for the controller placement. The algorithms that were used were tested successfully in an SDN network with 1 controller, 5 switches and 6 nodes. 
When they introduced second controller into the network, then the performance of the system was improved by 35 percent. When they tried to add one controller to a network with 3 controllers, 15 switches and 18 nodes, then the performance of the system was improved only by 9 percent. Few tests with worst locations for the controller positioning, showed the same level of performance but for most of the tests that were run, they showed improvements in the performance. Therefore, there was a need to obtain an optimum placement of controller for implementing and testing the limited simulated environment of SDN.

\subsection{Survey of CPP in SDN:}

The further survey of CPP in SDN was done in the year 2019, by Jie Lu, et al. [39]. At first, they introduced the overview of SDN and CPP in their work. Then, they classified their research work into the four different aspects of the CPP, which were: a) latency, b) reliability, c) cost and d) multi-objective. After this, they identified some relevant issues and research challenges that dealt with the future work of CPP. For each category, the authors analyzed the cause of the optimization goal and the impacts that occurred on the network performance. Then after this analysis, they introduced the representative models which further resulted for the detailed analysis for different applications and their scenarios [40].

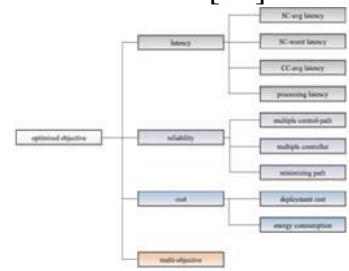

Fig. 20. Classification of Objective that has been optimized [39].

It was also observed that for each optimized objective, the exhaustive scenarios were being analyzed. At last, some representatives and up-to-date models were being introduced with solving methods, relative merits and results.

\subsection{Controller Placement and Selection strategy for} SDN:

The next approach by R.K. Dasa et al. in March 2019 [41], condensed the methods that were used for evaluating the different approaches of Controller Placement Problem (CPP) and the Controller Selection Problem (CSP). This method was implemented with respect to some newly formed networks like the 'Internet of Things'.

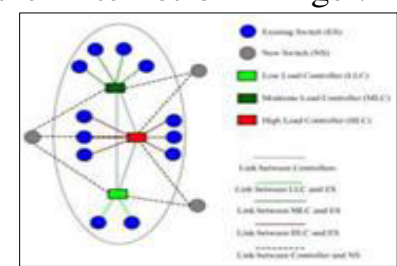

Fig. 21. Selection Process of SDN Controller [41].

In this work, a simpler yet effective approach for selecting the controller was being proposed. This proposed algorithm considered the load and the propagation delay as two most important aspects/parameters for the CSP. Under the known knowledge, the CPP and CSP are also known as the NP-Hard Problems.

\subsection{Binding-Less Architecture for Distributed Controllers (BLAC):}

In April 2019, V. Huang, et al. [42], tried to solve the controller placement problem which considered the factors like the: utilization of the control plane, communication delays and the distribution of the controller's workload. They developed an algorithm that integrated the optimization methods: Genetic Algorithm (GA) and Gradient Descent (GD).

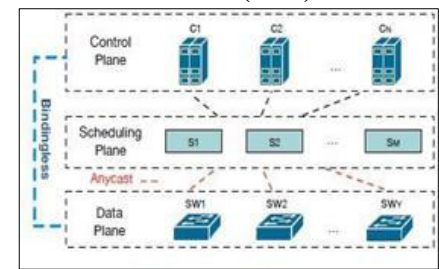

Fig. 22. BLAC System Architecture [42].

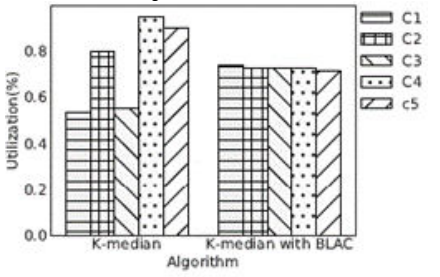

Fig. 23 Comparison between K-Median and Kmedian with BLAC for controller utilization [42]. With the help of BLAC, CPP was then addressed in a systematic manner. It was also observed that GD was purely used for the fitness evaluation of the given network. A queuing model was built, which was used to measure the relationship between the workload distribution, the network response time and the communication delay. The control plane utilization was also kept at a high level, so that the reasonable operation cost can be maintained. And at last, it was concluded that the algorithm used in this work achieved competitively low response time and higher control plane utilization when compared to the other widelyused heuristic methods.

\subsection{Sub-modularity optimization:}

As we already know, SDN has opened a promising and potential approach to- wards the future networks. With the high advantages of SDN, it has also become very crucial aspect for the implementation of the IoT services. So, researchers like A.K. Tran, et al. [43], introduced SDN controller's placement in IoT networks, using the sub-modularity based approach for optimization. They evaluated the IoT scenarios and their simulation result showed that the propagation algorithms can be used for outperforming the baseline methods in terms of the number of controllers, execution time and the network latency. 


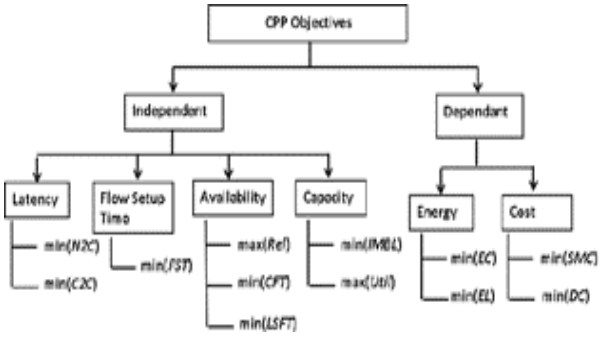

Fig. 24. CPP Metrics Classification [43].

An outstanding result of the framework in terms of the number of controllers, execution time and network latency were being demonstrated. In the perspective of the SDN controller in IoT networks, this framework was unable to obtain any relationship between controllers in the control channel, no matter how much the submodularapproach got matched with the CPP.

\subsection{Varna-based Optimization:}

In further research approaches, a new optimization technique called the 'Varna- based Optimization' came into existence for the CPP in SDN. This approach was considered by A.K. Singh et al., in December 2019 [44]. They developed a novel optimization algorithm called the Varna-Based Optimization (VBO) for solving the CPP. This approach was one of the first attempts that were used for the minimization of the total average latency of any Software Defined Network. This approach also implemented the TLBO and Jaya Algorithm, which were used for solving the Controller Placement Problem for some 12 possible scenarios. The results stated that the TLBO was better that PSO and VBO was much better than both TLBO and Jaya Algorithm in all topologies and all scenarios [45].

6.10 Parameter Optimization Model (POM) of heuristic algorithms for CPP in large-scale SDN: In August 2020, Yi Li et al, introduced the 'Parameter Optimization Model (POM)' of heuristic algorithms for CPP in large-scale SDN [46]. This algorithm effectively solved the CPP using the optimized parameters. The verification of the effectiveness of this algorithm was done.

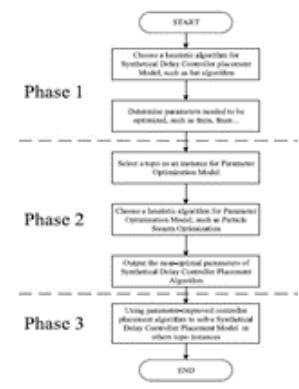

Fig. 25. Flow Chart for CPP Algorithm using Parameter Optimization Model [46].

The results show that compared with the original algorithms, in terms of the synthetical delay, the time consumption and the variance of synthetical delay, the TLBO [47], and the PSO, performed better which resulted in slowing down of POM [48]. Besides this,
POM can be also used for the optimization of the parameters of other heuristic algorithms to solve for CPP.

\subsection{Garter Snake Optimization Capacitated} Controller Placement Problem (GSOCCPP):

In November 2020, researchers S. Torkamani-Azar and M. Jahamshahi proposed a solution for these problems [49]. They considered the Knapsack 0-1 problem and formulated the Garter Snake Optimization Capacitated Controller Placement Problem (GSOCCPP).

The GSOCCPP is a meta-heuristic algorithm that consists of new iterations and solves the CPP with the help of temperate mating conditions.

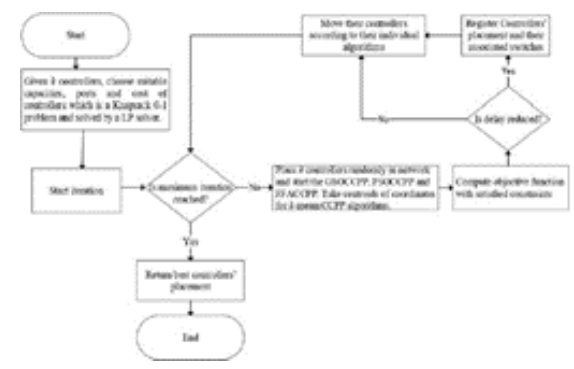

Fig. 26. Overall procedure for controller placement using the GSOCCPP algorithm [49].

The simulation results demonstrated that, the newly proposed GSOCCPPalgorithm was successful in achieving the lowest execution time among the analyzed algorithms when compared to the similar type of metaheuristic and clustering algorithms such as the Particle Swarm Optimization, Firefly Algorithmand the kmeans++ [50].

Furthermore, this proposed solution was a more efficient in the memory consumption when compared to other algorithms for controller placement in different network topologies.

\subsection{Placement of controller in the multi-control 5G based on SDN/NFV architecture:}

Recently, in December 2020, A. A. Z. Ibrahim, et al., developed allocation algorithm based on the heuristic approach for the placement of controller in the multicontrol 5G based on SDN/NFV architecture [51]. The integration of SDN and NFV is considered an efficient solution which enabled the forecasting of highly scalable and optimal performance of the $5 \mathrm{G}$ networks [52][53][54].

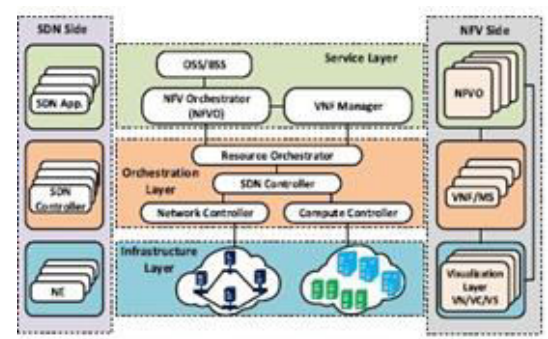

Fig. 27. Integrated SDN/NVF architecture [51]. 
They provide an effective means of network functionalities. This approach is primarily aiming to support network functions that perform with the help of applications of a control plane. It provided versatility to the network traffic management [55]. To address the CPP in distributed $5 \mathrm{G}$ network, dynamic capacitated controller placement problem (DCCPP) was being introduced. It was based on the K-center problem and was used to solve the capacitated controller placement problem (CCPP).

A Greedy Randomized Search (GRS) algorithm was introduced which helped in solving the dynamic assignments of the nodes to controllers for achieving the load balancing in controllers [56]-[60]. This approach also provided the network resource management and efficient cost management when compared to the basic CCPP model. It was observed that, an effective decentralized policy can help in achieving the higher degree of efficiency with the help of resource assignment ina dense network.

\section{ISSUES AND CHALLENGES:}

As future technologies, SDN and Network Function Virtualization (NFV) are key technologies to bring smart services to the current scenarios of IOT networks. One of the major challenges that need to be solved is placing an efficient control plane in the SDN. Another major challenge is to solve the problem of SDN controller placement in the field of Edge Computing. Since IOT is a growing area, there are still many topics for CPP in this area. Swarm Optimization and Firefly Optimization techniques in CPP are one of the important topics that should focused on. Controller Placement in 5Gnetworking is a current issue that must be solved. Work can also be done on the possibility of Communication between the switches when the link and nodes failure occur inside the networks.

\section{CONCLUSION:}

Software Defined Network (SDN) is used for providing a centralized view of the network as well as it is an emerging network paradigm that can be used for decoupling the network control plane from the data plane, i.e., to separate both the planes from each other. Implementation of SDN using a single physical controller leads to the issues of robustness and scalability inside the network.

Distributed SDN has a lot of benefits but it also has the problem of considering the number of controllers required and the placement of those controllers inside the network. This problem itself is known as "The Controller Placement Problem (CPP)" which is also an NP-hard problem and which purely depends on the type of the network being considered. Solutions to the CPP are completely dependent on wireless and wired net- works.
There are mainly two results of a solution to the CPP that can be observed:

1. Placement of the controllers, and

2. Mapping (or binding) of switches to a controller.

In any other distributed Software Defined Network, the architecture of the controllers and the performance of the network mainly depend on the controller's placement inside the network. In Software Defined Network that consists of a single physical controller, the placement of the controllers is considered to be one of the major issues. Heller et al. and his team were the first ones to perform research on this issue of CPP in SDN. They formulated the controller placement problem to be a facility location problem. The CPP was also shown to be an NP-hard problem.

Since then, there has been n-number of efforts that are done to place the controllers optimally inside the network. We also studied about the optimization frameworks under the well-known theories, in the IoT scenarios. In latest researches, we came to know about the introduction of a novel method named Garter Snake Optimization Capacitated Controller Placement Problem (GSOCCPP) for obtaining the near-optimal minimal propagation delays in the Capacitated Controller Placement Problems. Also, it was observed that, an effective decentralized policy can help in achieving the higher degree of efficiency with the help of resource assignment in a dense network in $5 \mathrm{G}$ based SDN/NVF network architectures. Hence, we have studied about almost all the work done on the Controller Placement Problem in the Software Defined Networks. 
TABLE 4. Key Points to be considered for the controller placement problem in SDN.

\begin{tabular}{|c|c|c|c|c|c|c|c|}
\hline References & $\begin{array}{c}\text { Switch to } \\
\text { Controller } \\
\end{array}$ & Scalability & $5 G$ & WANs & $\begin{array}{c}\text { Load } \\
\text { Balancing } \\
\end{array}$ & $\begin{array}{l}\text { Heuristic } \\
\text { Approach } \\
\end{array}$ & $\begin{array}{c}\text { Other } \\
\text { Approach } \\
\end{array}$ \\
\hline B. Kamal et.al. ${ }^{[2]}$ & $\checkmark$ & $x$ & $x$ & $x$ & $x$ & $x$ & $\checkmark$ \\
\hline D. Kreutz et. al. ${ }^{[3]}$ & $\checkmark$ & $x$ & $x$ & $x$ & $x$ & $x$ & $\checkmark$ \\
\hline$\underset{[5]}{\text { R. G. Clegg et. al. }}$ & $\checkmark$ & $x$ & $x$ & $x$ & $x$ & $x$ & $\checkmark$ \\
\hline D. Hock et. al. ${ }^{[9]}$ & $x$ & $x$ & $x$ & $x$ & $x$ & $\checkmark$ & $x$ \\
\hline Y. Jimenez et. al. & $x$ & $x$ & $x$ & $x$ & $\checkmark$ & $x$ & $\checkmark$ \\
\hline S. Lange et. al. ${ }^{[15]}$ & $x$ & $\checkmark$ & $x$ & $x$ & $x$ & $\checkmark$ & $x$ \\
\hline$\underset{[16]}{\text { E. Borcoci et. al. }}$ & $x$ & $\checkmark$ & $x$ & $\checkmark$ & $\checkmark$ & $x$ & $\checkmark$ \\
\hline S. Lange et. al. ${ }^{[17]}$ & $x$ & $x$ & $x$ & $x$ & $x$ & $\checkmark$ & $x$ \\
\hline$\underset{[21]}{\text { E. Borcoci et. al. }}$ & $x$ & $\checkmark$ & $x$ & $x$ & $x$ & $\checkmark$ & $x$ \\
\hline$\underset{[27]}{\text { Peng Xiao et. at. }}$ & $x$ & $\checkmark$ & $x$ & $\checkmark$ & $x$ & $x$ & $\checkmark$ \\
\hline A. Ksentini et. al. & $x$ & $x$ & $\checkmark$ & $x$ & $x$ & $x$ & $\checkmark$ \\
\hline T. Hu et. al. ${ }^{[34]}$ & $x$ & $\checkmark$ & $x$ & $x$ & $\checkmark$ & $x$ & $\checkmark$ \\
\hline $\begin{array}{l}\text { N. Mouawad et. } \\
\text { al. }{ }^{[37]}\end{array}$ & $x$ & $x$ & $\checkmark$ & $x$ & $x$ & $x$ & $\checkmark$ \\
\hline$\underset{[38]}{\text { E. Borcoci et. al. }}$ & $x$ & $x$ & $x$ & $\checkmark$ & $x$ & $x$ & $\checkmark$ \\
\hline Y. Li et. al. ${ }^{[46]}$ & $\checkmark$ & $x$ & $x$ & $x$ & $x$ & $\checkmark$ & $x$ \\
\hline $\begin{array}{l}\text { A. A. Z. Ibrahim } \\
\text { et. al. }\end{array}$ & $x$ & $x$ & $\checkmark$ & $x$ & $x$ & $\checkmark$ & $x$ \\
\hline N. Cai et. al. ${ }^{[60]}$ & $x$ & $x$ & $\checkmark$ & $x$ & $\checkmark$ & $x$ & $\checkmark$ \\
\hline
\end{tabular}


TABLE 5. Comparative analysis of the controller placement problem in software defined networks.

\begin{tabular}{|c|c|c|c|c|c|c|c|}
\hline $\begin{array}{l}\text { S. } \\
\text { No. }\end{array}$ & References & $\begin{array}{l}\text { Placement } \\
\text { Standard }\end{array}$ & Used Topology & $\begin{array}{c}\text { Static/ } \\
\text { Dynamic }\end{array}$ & $\begin{array}{l}\text { Algorithm for } \\
\text { Solution }\end{array}$ & $\begin{array}{c}\text { Network Size } \\
\text { and Network } \\
\text { Partitioning } \\
\text { (Yes/No) }\end{array}$ & $\begin{array}{c}\text { Traffic and } \\
\text { load } \\
\text { Balancing } \\
\text { (Yes/No) }\end{array}$ \\
\hline \multirow{2}{*}{1.} & \multirow{2}{*}{$\begin{array}{l}\text { B.Heller } \\
\text { et.al. }^{[6]}\end{array}$} & K-Median & \multirow{2}{*}{ Internet2 OS3E } & \multirow{2}{*}{ Static } & \multirow{2}{*}{$\begin{array}{l}\text { Placing } \\
\text { controllers } \\
\text { randomly }\end{array}$} & \multirow{2}{*}{$\begin{array}{l}\text { Large sized } \\
\text { network- No }\end{array}$} & \multirow{2}{*}{ No } \\
\hline & & K-Center & & & & & \\
\hline \multirow[b]{2}{*}{2.} & \multirow[b]{2}{*}{$\begin{array}{l}\text { Yan Hu et. } \\
\text { al. }^{[8]}\end{array}$} & \multirow{2}{*}{$\begin{array}{l}\text { Reliability } \\
\text { aware } \\
\text { Controller } \\
\text { Placement }\end{array}$} & Rocket fuel & \multirow[b]{2}{*}{ Static } & $\begin{array}{c}\text { 1-w greedy } \\
\text { solution }\end{array}$ & \multirow{2}{*}{$\begin{array}{c}\text { Small and } \\
\text { medium sized } \\
\text { network- No }\end{array}$} & \multirow[b]{2}{*}{ No } \\
\hline & & & Internet2OS3E & & $\begin{array}{l}\text { Placing } \\
\text { controllers } \\
\text { randomly }\end{array}$ & & \\
\hline 3. & $\begin{array}{l}\text { D. Hock et. } \\
\text { al. }{ }^{[9]}\end{array}$ & K-Center & Interner2OS3E & Static & $\begin{array}{l}\text { Pareto-based } \\
\text { Optimal } \\
\text { Controller } \\
\text { Placement } \\
\text { (POCO) }\end{array}$ & $\begin{array}{c}\text { Small and } \\
\text { medium sized } \\
\text { network- No }\end{array}$ & Yes \\
\hline 4. & $\begin{array}{l}\text { Guang Yao } \\
\text { et. al. }\end{array}$ & $\begin{array}{l}\text { K- Median } \\
\text { Deployment }\end{array}$ & Switch-based & Static & $\begin{array}{l}\text { Multi-controller } \\
\text { based. }\end{array}$ & $\begin{array}{l}\text { Large sized } \\
\text { network- No }\end{array}$ & Yes \\
\hline \multirow{2}{*}{5.} & \multirow{2}{*}{$\begin{array}{l}\text { Y. Jimenez } \\
\text { et. al. }{ }^{[12]}\end{array}$} & K-median & \multirow{2}{*}{$\begin{array}{c}\text { Sparse, } \\
\text { Medium, Dense } \\
\text { Network } \\
\text { Topology }\end{array}$} & \multirow{2}{*}{ Dynamic } & \multirow{2}{*}{$\begin{array}{l}\text { K-Critical } \\
\text { algorithm }\end{array}$} & \multirow{2}{*}{$\begin{array}{l}\text { Large-sized } \\
\text { network- No }\end{array}$} & \multirow{2}{*}{ Yes } \\
\hline & & K-Center & & & & & \\
\hline \multirow[b]{2}{*}{6.} & \multirow{2}{*}{$\begin{array}{l}\text { Guang Yao } \\
\text { et. al. }\end{array}$} & K-Center & \multirow{2}{*}{$\begin{array}{c}\text { Internet } \\
\text { Topology Zoo }\end{array}$} & \multirow[b]{2}{*}{ Dynamic } & \multirow{2}{*}{$\begin{array}{l}\text { Linear } \\
\text { relaxation } \\
\text { algorithm }\end{array}$} & \multirow{2}{*}{$\begin{array}{l}\text { Large-sized } \\
\text { network- No }\end{array}$} & \multirow[b]{2}{*}{ Yes } \\
\hline & & Capacitated & & & & & \\
\hline \multirow[t]{2}{*}{7.} & \multirow{2}{*}{$\begin{array}{l}\text { S. Lange et. } \\
\text { al. }{ }^{[15]}\end{array}$} & K-Median & \multirow[t]{2}{*}{ Interner2OS3E } & \multirow[t]{2}{*}{ Dynamic } & \multirow{2}{*}{$\begin{array}{l}\text { Pareto Optimal } \\
\text { Simulated } \\
\text { Solution }\end{array}$} & \multirow{2}{*}{$\begin{array}{l}\text { Large-sized } \\
\text { network- No }\end{array}$} & \multirow[t]{2}{*}{ Yes } \\
\hline & & K-Center & & & & & \\
\hline & & $\begin{array}{c}\text { Performance- } \\
\text { only related } \\
\text { metrics }\end{array}$ & & & $\begin{array}{c}\text { Multi- } \\
\text { Controller }\end{array}$ & & \\
\hline 8. & $\begin{array}{l}\text { E. Borococi } \\
\text { et. al. }{ }^{[16]}\end{array}$ & $\begin{array}{l}\text { Reliability- } \\
\text { aware }\end{array}$ & $\begin{array}{c}\text { Internet } \\
\text { Topology Zoo }\end{array}$ & Dynamic & $\begin{array}{c}\text { based } \\
\text { Optimization }\end{array}$ & $\begin{array}{l}\text { Wide Area } \\
\text { network- No }\end{array}$ & Yes \\
\hline & & $\begin{array}{c}\text { Multi-path } \\
\text { connectivity }\end{array}$ & & & algorithm & & \\
\hline 9. & $\begin{array}{l}\text { S. Lange et. } \\
\text { al. }{ }^{[17]}\end{array}$ & K- Medoids & $\begin{array}{c}\text { Internet } \\
\text { Topology Zoo }\end{array}$ & Dynamic & $\begin{array}{l}\text { Pareto } \\
\text { Capacitated k- } \\
\text { Medoids }\end{array}$ & $\begin{array}{l}\text { Large-sized } \\
\text { network- No }\end{array}$ & Yes \\
\hline 10. & $\begin{array}{l}\text { Huque Md } \\
\text { et. al. }{ }^{[20]}\end{array}$ & LiDy & $\begin{array}{l}\text { Large- Sized } \\
\text { network } \\
\text { topology }\end{array}$ & Dynamic & LiDy & $\begin{array}{c}\text { Large-sized } \\
\text { networks-No }\end{array}$ & Yes \\
\hline & & $\begin{array}{c}\text { Performance- } \\
\text { only related } \\
\text { metrics }\end{array}$ & & & Multi-Criteria & & \\
\hline 11. & $\begin{array}{l}\text { E. Borococ1 } \\
\text { et. al. }{ }^{[21]}\end{array}$ & $\begin{array}{c}\text { Reliability- } \\
\text { aware }\end{array}$ & $\begin{array}{c}\text { Internet } \\
\text { Topology Zoo }\end{array}$ & Dynamic & $\begin{array}{c}\text { based } \\
\text { Optimization }\end{array}$ & $\begin{array}{l}\text { Large-sized } \\
\text { network- No }\end{array}$ & Yes \\
\hline & & $\begin{array}{l}\text { Multi-path } \\
\text { connectivity }\end{array}$ & & & & & \\
\hline 12. & $\begin{array}{c}\text { Aoki et. al. } \\
{[23]}\end{array}$ & K- Median & $\begin{array}{l}\text { Variable sized } \\
\text { topology }\end{array}$ & Dynamic & $\begin{array}{l}\text { PSO-CGL } \\
\text { Controller } \\
\text { Placement } \\
\text { Problem }\end{array}$ & $\begin{array}{c}\text { Large-sized } \\
\text { network- Yes }\end{array}$ & Yes \\
\hline
\end{tabular}




\begin{tabular}{|c|c|c|c|c|c|c|c|}
\hline \multirow[t]{2}{*}{13.} & \multirow{2}{*}{$\begin{array}{l}\text { Jiang Liu et. } \\
\text { al. }{ }^{25]}\end{array}$} & \multirow{2}{*}{$\begin{array}{l}\text { Reliability } \\
\text { Based }\end{array}$} & $\begin{array}{c}\text { Internet } \\
\text { Topology Zoo } \\
\end{array}$ & \multirow[t]{2}{*}{ Dynamic } & \multirow{2}{*}{$\begin{array}{l}\text { Greedy } \\
\text { algorithm }\end{array}$} & \multirow{2}{*}{$\begin{array}{l}\text { Large-sized } \\
\text { network- Yes }\end{array}$} & \multirow[t]{2}{*}{ Yes } \\
\hline & & & Internet2 OS3E & & & & \\
\hline 14. & $\begin{array}{l}\text { Peng Xiao } \\
\text { et. al. }{ }^{[27]}\end{array}$ & $\begin{array}{c}\text { K-Self } \\
\text { adaptive }\end{array}$ & Internet2 OS3E & Dynamic & $\begin{array}{c}\text { Spectral } \\
\text { Clustering }\end{array}$ & $\begin{array}{c}\text { Large-sized } \\
\text { network- Yes }\end{array}$ & Yes \\
\hline 15. & $\begin{array}{l}\text { Jianxin Liao } \\
\text { et. al. }{ }^{[29]}\end{array}$ & $\begin{array}{l}\text { Density- based } \\
\text { controller } \\
\text { placement }\end{array}$ & $\begin{array}{c}\text { Internet } \\
\text { Topology Zoo }\end{array}$ & Dynamic & $\begin{array}{l}\text { Density based } \\
\text { clustering }\end{array}$ & $\begin{array}{c}\text { Large scale } \\
\text { network- Yes }\end{array}$ & Yes \\
\hline 16. & $\begin{array}{l}\text { A. Ksentini } \\
\text { et. al. }{ }^{[31]}\end{array}$ & $\begin{array}{l}\text { Serving } \\
\text { Gateway } \\
\text { SGW-C }\end{array}$ & $\begin{array}{l}\text { Variable sized } \\
\text { topology }\end{array}$ & Dynamic & $\begin{array}{l}\text { Pareto-Optimal } \\
\text { Solution }\end{array}$ & $\begin{array}{c}\text { 5G/LTE } \\
\text { network- Yes }\end{array}$ & Yes \\
\hline 17. & $\begin{array}{l}\text { Sood and } \\
\text { Xiang }\end{array}$ & $\begin{array}{l}\text { Potential } \\
\text { selection }\end{array}$ & $\begin{array}{l}\text { Variable sized } \\
\text { topology }\end{array}$ & Dynamic & $\begin{array}{l}\text { Controller } \\
\text { selection }\end{array}$ & $\begin{array}{l}\text { Large-sized } \\
\text { network } \\
\text { No }\end{array}$ & $\begin{array}{c}\text { Not } \\
\text { discussed }\end{array}$ \\
\hline \multirow{3}{*}{18.} & \multirow{3}{*}{ T. Hue y. al. } & \multirow{3}{*}{$\begin{array}{c}\text { Multi- } \\
\text { Controller } \\
\text { based metrices }\end{array}$} & \multirow{3}{*}{ Internet2 OS3E } & \multirow{3}{*}{ Dynamic } & Robust Control & \multirow{3}{*}{$\begin{array}{c}\text { Large-sized } \\
\text { network- Yes }\end{array}$} & \multirow{3}{*}{ Yes } \\
\hline & & & & & $\begin{array}{c}\text { Optimal } \\
\text { Controller } \\
\text { placement }\end{array}$ & & \\
\hline & & & & & $\begin{array}{l}\text { Capacitated } \\
\text { Controller }\end{array}$ & & \\
\hline \multirow{3}{*}{19.} & \multirow{3}{*}{$\begin{array}{l}\text { A. } \\
\text { Alshamrani } \\
\text { et. al. }{ }^{[36]}\end{array}$} & \multirow{3}{*}{$\begin{array}{l}\text { Robust metric } \\
\text { for fault- } \\
\text { tolerance }\end{array}$} & $\begin{array}{c}\text { Internet } \\
\text { Topology Zoo }\end{array}$ & \multirow{3}{*}{ Dynamic } & \multirow{3}{*}{$\begin{array}{l}\text { Fault Tolerant } \\
\text { Controller } \\
\text { Placement }\end{array}$} & \multirow{3}{*}{$\begin{array}{l}\text { Large-sized } \\
\text { network- Not } \\
\text { Discussed }\end{array}$} & \multirow{3}{*}{ Yes } \\
\hline & & & $\begin{array}{c}\text { Generic } \\
\text { Topology }\end{array}$ & & & & \\
\hline & & & $\begin{array}{l}\text { Straight-line } \\
\text { Topology }\end{array}$ & & & & \\
\hline \multirow{3}{*}{20.} & \multirow{3}{*}{$\begin{array}{c}\text { N. } \\
\text { Mouawad } \\
\text { et. al. }{ }^{[37]}\end{array}$} & $\begin{array}{l}\text { Connectivity } \\
\text { metrics }\end{array}$ & $\begin{array}{c}\text { Internet } \\
\text { Topology Zoo }\end{array}$ & \multirow{3}{*}{ Dynamic } & $\begin{array}{c}\text { Optimal } \\
\text { Controller } \\
\text { Placement }\end{array}$ & \multirow{3}{*}{$\begin{array}{l}\text { Large-sized } \\
\text { network- No }\end{array}$} & \multirow{3}{*}{ Yes } \\
\hline & & \multirow[b]{2}{*}{$\begin{array}{l}\text { Latency } \\
\text { metrics }\end{array}$} & Internet2 OS3E & & $\begin{array}{c}\text { Load Balancing } \\
\text { Algorithm }\end{array}$ & & \\
\hline & & & $\begin{array}{l}\text { NSFNET } \\
\text { topology }\end{array}$ & & $\begin{array}{l}\text { Switch- } \\
\text { Migration } \\
\text { Algorithm }\end{array}$ & & \\
\hline \multirow{4}{*}{21.} & \multirow{4}{*}{ J. Lu et. al. } & \multirow{4}{*}{$\begin{array}{l}\text { Multiple } \\
\text { performance } \\
\text { metrics }\end{array}$} & \multirow{4}{*}{$\begin{array}{c}\text { Internet } \\
\text { Topology Zoo }\end{array}$} & \multirow{4}{*}{ Dynamic } & $\begin{array}{l}\text { Multi-criteria } \\
\text { decision } \\
\text { algorithm }\end{array}$ & \multirow{4}{*}{$\begin{array}{c}\text { Large-sized } \\
\text { network- Yes }\end{array}$} & \multirow{4}{*}{ Yes } \\
\hline & & & & & $\begin{array}{l}\text { Bargaining } \\
\text { game }\end{array}$ & & \\
\hline & & & & & $\begin{array}{l}\text { Multi-start } \\
\text { hybrid non- } \\
\text { dominated } \\
\text { sorting genetic } \\
\text { algorithm } \\
\text { (MHNSA) }\end{array}$ & & \\
\hline & & & & & $\begin{array}{l}\text { Adaptive } \\
\text { bacterial } \\
\text { foraging } \\
\text { optimization }\end{array}$ & & \\
\hline 22. & $\begin{array}{l}\text { Rohit Das } \\
\text { et. al. }{ }^{[41]}\end{array}$ & $\begin{array}{c}\text { Load } \\
\text { Controllers }\end{array}$ & $\begin{array}{c}\text { Internet } \\
\text { Topology Zoo }\end{array}$ & Dynamic & $\begin{array}{l}\text { Dynamic Flow } \\
\text { Management } \\
\text { algorithm } \\
\text { (DyFlow) }\end{array}$ & $\begin{array}{l}\text { Large-sized } \\
\text { network-Yes }\end{array}$ & Yes \\
\hline
\end{tabular}




\begin{tabular}{|c|c|c|c|c|c|c|c|}
\hline \multirow{4}{*}{23.} & \multirow{4}{*}{$\begin{array}{l}\text { V. Huang et. } \\
\text { al. }{ }^{[42]}\end{array}$} & K-Median & \multirow{4}{*}{$\begin{array}{l}\text { Fat-tree } \\
\text { Topology }\end{array}$} & \multirow{4}{*}{ Dynamic } & Random & \multirow{4}{*}{$\begin{array}{l}\text { Large-sized } \\
\text { network- Not } \\
\text { discussed }\end{array}$} & \multirow{4}{*}{ Yes } \\
\hline & & \multirow{3}{*}{$\begin{array}{l}\text { K-Median with } \\
\text { Gradient } \\
\text { Descent (GD) }\end{array}$} & & & $\begin{array}{c}\text { Capacity-based } \\
\text { Greedy } \\
\text { Algorithm }\end{array}$ & & \\
\hline & & & & & $\begin{array}{l}\text { K-Median } \\
\text { Approach }\end{array}$ & & \\
\hline & & & & & $\begin{array}{c}\text { Direct } \\
\text { Optimization } \\
\text { Approach } \\
\end{array}$ & & \\
\hline \multirow{3}{*}{24.} & \multirow{3}{*}{$\begin{array}{l}\text { Tran, Anh } \\
\text { et. al. }{ }^{[43]}\end{array}$} & \multirow{3}{*}{$\begin{array}{c}\text { Heuristic and } \\
\text { sub- } \\
\text { modularity- } \\
\text { based approach }\end{array}$} & \multirow{3}{*}{$\begin{array}{l}\text { Network } \\
\text { Topology }\end{array}$} & \multirow{3}{*}{ Dynamic } & $\begin{array}{l}\text { Nemhauser's } \\
\text { Algorithm }\end{array}$ & \multirow{3}{*}{$\begin{array}{l}\text { IoT Networks- } \\
\text { Not discussed }\end{array}$} & \multirow{3}{*}{$\begin{array}{c}\text { Not } \\
\text { discussed }\end{array}$} \\
\hline & & & & & $\begin{array}{l}\text { Search tree } \\
\text { algorithm }\end{array}$ & & \\
\hline & & & & & $\begin{array}{c}\text { Closest-distance } \\
\text { algorithm }\end{array}$ & & \\
\hline \multirow{3}{*}{25.} & \multirow{3}{*}{$\begin{array}{l}\text { A.K. Singh } \\
\text { et. al. }{ }^{[4]]}\end{array}$} & \multirow{3}{*}{$\begin{array}{l}\text { Capacitated } \\
\text { controller } \\
\text { placement }\end{array}$} & \multirow{3}{*}{$\begin{array}{l}\text { All Network } \\
\text { Topologies }\end{array}$} & \multirow{3}{*}{ Dynamic } & $\begin{array}{c}\text { Varna-based } \\
\text { Optimization }\end{array}$ & \multirow{3}{*}{$\begin{array}{l}\text { Large-sized } \\
\text { Network- No }\end{array}$} & \multirow{3}{*}{$\begin{array}{c}\text { Not } \\
\text { discussed }\end{array}$} \\
\hline & & & & & $\begin{array}{c}\text { TLBO } \\
\text { algorithm }\end{array}$ & & \\
\hline & & & & & Jaya Algorithm & & \\
\hline \multirow{4}{*}{26.} & \multirow{4}{*}{ Y. Li et. al. } & \multirow{4}{*}{$\begin{array}{l}\text { Parameter } \\
\text { Optimization } \\
\text { model }\end{array}$} & Internet2 OS3E & \multirow{4}{*}{ Dynamic } & $\begin{array}{l}\text { BACPA } \\
\text { algorithm }\end{array}$ & \multirow{4}{*}{$\begin{array}{l}\text { Large Scale- } \\
\text { Software } \\
\text { Defined } \\
\text { Networks- Not } \\
\text { discussed }\end{array}$} & \multirow{4}{*}{ Yes } \\
\hline & & & \multirow{3}{*}{$\begin{array}{c}\text { Internet } \\
\text { Topology Zoo }\end{array}$} & & $\begin{array}{c}\text { FACPA } \\
\text { algorithm }\end{array}$ & & \\
\hline & & & & & $\begin{array}{l}\text { VBOCPA } \\
\text { algorithm }\end{array}$ & & \\
\hline & & & & & $\begin{array}{l}\text { PSO based } \\
\text { parameter } \\
\text { Algorithm } \\
\end{array}$ & & \\
\hline \multirow{4}{*}{27.} & \multirow{4}{*}{$\begin{array}{c}\text { Sahand } \\
\text { Torkamani- } \\
\text { Azar et. al. } \\
{\left[{ }^{4} 9\right]}\end{array}$} & \multirow{4}{*}{ K-Mean } & \multirow{4}{*}{$\begin{array}{c}\text { Internet } \\
\text { Topology Zoo }\end{array}$} & \multirow{4}{*}{ Dynamic } & $\begin{array}{l}\text { FFACCPP } \\
\text { algorithm }\end{array}$ & & \\
\hline & & & & & $\begin{array}{l}\text { PSOCCPP } \\
\text { algorithm }\end{array}$ & Wide-Area & Yes \\
\hline & & & & & $\begin{array}{l}\text { K-Means CCPP } \\
\text { algorithm }\end{array}$ & Networks- Yes & \\
\hline & & & & & GSOCCPP & & \\
\hline & & & & & $\begin{array}{l}\text { K-Center } \\
\text { Algorithm } \\
\end{array}$ & & \\
\hline & & & & & GRS algorithm & & \\
\hline & & & & & $\begin{array}{c}\text { Dynamic } \\
\text { Optimization } \\
\text { Algorithm } \\
\end{array}$ & & \\
\hline 28. & $\begin{array}{l}\text { A. A. Z. } \\
\text { Ibrahim et. } \\
\text { al. [51] }\end{array}$ & K- Center & $\begin{array}{l}\text { Network } \\
\text { Topology }\end{array}$ & Dynamic & $\begin{array}{l}\text { Slap Swarm } \\
\text { Optimization } \\
\text { Algorithm } \\
\text { (SSOA) } \\
\end{array}$ & $\begin{array}{c}\text { 5G SDN NFV- } \\
\text { based network- } \\
\text { Yes }\end{array}$ & Yes \\
\hline & & & & & $\begin{array}{l}\text { Heuristic } \\
\text { Resource } \\
\text { Allocation } \\
\text { Algorithm } \\
\end{array}$ & & \\
\hline & & & & & $\begin{array}{c}\text { DCCPP } \\
\text { Algorithm }\end{array}$ & & \\
\hline
\end{tabular}




\section{REFERENCES}

[1] Wenfeng Xia, Yonggang Wen, Chuan Heng Foh, Dusit Niyato and Haiyong Xie, "A Survey on Software-Defined Networking," IEEE Communication Surveys and Tutorials, Vol.17, No.1, First Quarter 2015.

[2] Benzekki, Kamal; El Fergougui, Abdeslam; Elbelrhiti Elalaoui, Abdelbaki. "Software-defined networking (SDN): A survey". Security and Communication Networks. 9(18):58035833, 2016.

[3] D. Kreutz, F. M. V. Ramos, P. E. Ver'1ssimo, C. E. Rothenberg, S. Azodolmolky and S. Uhlig, "Software-Defined Networking: A Comprehensive Survey," in Proceedings of the IEEE, vol. 103, no. 1, pp. 14-76, Jan. 2015.

[4] N. Mckeown, How SDN will shape networking, Oct. 2011.

[5] R. G. Clegg, J. Spencer, R. Landa, M. Thakur, J. Mitchell, M. Rio, "Pushing software defined networking to the access", Proc. 3rd Eur. Workshop Softw. Defined Netw., pp. 1-6, 2014.

[6] B. Heller, R. Sherwood, and N. McKeown, "controller placement problem," in Proc. HotSDN, 2012, pp. 7-12. Retrieved October 12,2020.

[7] S. Knight, N. Falkner, H. X. Nguyen, P. Tune and M. Roughan, "I can see for miles: Re-visualizing the internet," in IEEE Network, vol. 26, no. 6, pp. 26-32, November-December 2012.

[8] Y. Hu, W. Wendong, X. Gong, X. Que and C. Shiduan, "Reliability-aware con- troller placement for Software-Defined Networks," 2013 IFIP/IEEE International Symposium on Integrated Network Management (IM 2013), Ghent, 2013, pp. 672- 675.

[9] D. Hock, M. Hartmann, S. Gebert, M. Jarschel, T. Zinner and P. Tran-Gia, "Pareto-optimal resilient controller placement in SDN-based core networks," Proceedings of the 2013 25th International Teletraffic Congress (ITC), Shanghai, 2013, pp. 1-9.

[10] Guang Yao, Jun Bi and Luyi Guo, "On the cascading failures of multi-controllers in Software Defined Networks," 2013 21st IEEE International Conference on Network Protocols (ICNP), Goettingen, 2013, pp. 1-2.

[11] T. Koponen, M. Casado, N. Gude, J. St ribling, L. Pout ievski, M. Zhu, R. Ra- manathan, Y. Iwata, H. Inoue, T. Hama, and S. Shenker. "ONIX: a distributed control plat form for large-scale production networks." OSDI'10, , Berkeley, CA, USA, 2010, pages 1-6.

[12] Y. Jimenez, C. Cervello-Pastor and A. J. Garcia, "On the controller placement for designing a distributed SDN control layer," 2014 IFIP Networking Conference, Trondheim, 2014, pp. 1-9. [13] Yan-nan HU, Wen-dong WANG, Xiang-yang GONG, Xirong QUE, Shi-duan CHENG. "On placement of controllers in software-defined networks", The Journal of China Universities of Post and Telecommunications, vol. 19, no 2, pp. 92-97, Oct. 2012.
[14] G. Yao, J. Bi, Y. Li and L. Guo, "On the Capacitated Controller Placement Problem in Software Defined Networks," in IEEE Communications Letters, vol. 18, no. $\quad 8$, pp. 1339 1342, Aug. 2014.

[15] S. Lange, S. Gebert, T. Zinner, P. Tran-Gia, D. Hock, M. Jarschel, M. Hoffmann, "Heuristic Approaches to the Controller Placement Problem in Large Scale SDN Networks," in IEEE Transactions on Network and Service Management, vol. 12, no. 1, pp. 4-17, March 2015.

[16] E. Borcoci, R. Badea, S. G. Obreja, and M. Vochin, "On Multi-controller Placement Optimization in Software Defined Networking - based WANs", The International Symposium on Advances in Software Defined Networks SOFTNETWORKING 2015, Barcelona, Spain, retrieved: 1, 2016.

[17] S. Lange, S. Gebret, J, Spoerhase, P. Rygielski, T. Zinner, S. Kounev and P. Tran-Gia. "Specialized Heuristics for the Controller Placement Problem in Large Scale SDN Networks," 2015 27th International Teletraffic Congress, Ghent, 2015, pp. 210- 218.

[18] A. Basta, W. Kellerer, M. Hoffmann, H. J. Morper, and K. Hoffmann, "Applying NFV and SDN to LTE mobile core gateways, the functions placement problem," in Proceedings of the 4th workshop on All things cellular, 2014.

[19] Ehrgott, Matthias. "Multi objective Optimization". AI Magazine. 29.47-57.10.1007/9780-387-76635-5-6, 2008, Retrieved October 12,2020.

[20] Huque, Md Tanvir Ishtaiqueul Jourjon, Guillaume Gramoli, Vincent. (2015). "Revisiting the Controller Placement Problem." Retrieved October 12,2020.

[21] Borcoci, Eugen Ambarus, Tudor Vochin, Marius. "Multi-criteria based Optimization of Placement for Software Defined Networking Controllers and Forwarding Nodes". The Fifteenth International Conference on Networks SOFTNETWORKING, 2016.

[22] M. T. I. ul Huque, G Jourjon, V. Gramoli, "Revisiting the controller placement problem", NICTA, Australia. Tech. Rep. 2015. Retrieved October 12,2020.

[23] Aoki, Hidenobu and N. Shinomiya. "Controller Placement Problem to Enhance Performance in Multi-domain SDN Networks." 2016.

[24] H. Aoki and N. Shinomiya, "Network partitioning problem for effective management of multi-domain sdn networks," vol. 38, no. 8. IARIA, 2015, pp. 171-181

[25] Liu, Jiang Xie, Renchao. "Reliability-based controller placement algorithm in software defined networking." Computer Science and Information Systems, 2016. 
[26] Rebagliati, N., Verri, A. "Spectral clustering with more than K eigenvectors." Neurocomputing, 74(9):1391-1401, 2011.

[27] Peng Xiao, Zhi-Yang Li, Song Guo, Heng Qi, Wen-yu Qu, Hai-sheng Yu. "A K self-adaptive SDN controller placement for wide area networks." Frontie Inf Technol Electronic Eng 17,620633 (2016) Retrieved October 12, 2020.

[28] Bach, F.R., Jordan, M.I. "Learning Spectral Clustering." Technical Report, No. UCB/CSD-031249. University of California at Berkeley, USA, 2003.

[29] Jianxin Liao, Haifeng Sun, Jingyu Wang, Qi Qi, Kai Li, Tonghong Li. "Density cluster-based approach for controller placement problem in largescale software defined networkings", Computer Networks, 2016.10.014.

[30] Y. Zhang, N. Beheshti, M. Tatipamula. "On resilience of split-architecture networks", Global Telecommunications Conference

( GLOBECOM 2011), 2011 IEEE, 2011, pp. 1-6.

[31] A. Ksentini, M. Bagaa and T. Taleb, "On Using SDN in 5G: The Controller Placement Problem," 2016 IEEE Global Communications Conference (GLOBECOM), Washington, DC, 2016, pp. 1-6.

[32] T. Taleb, M. Corici, C. Parada, A. Jamakovic, S. Ruffino, G. Karagiannis, and T. Magedanz, "EASE: EPC as a Service to Ease Mobile Core Network," IEEE Network Magazine, Vol. 29, No. 2, Mar. 2015. pp.78- 88.

[33] Sood, K., Xiang, Y. "The controller placement problem or the controller selection problem?". $J$. Commun. Inf. Netw. 2, 19 (2017).

[34] T. Hu, Z. Guo, P. Yi, T. Baker and J. Lan, "Multi-controller Based Software-Defined Networking: A Survey," IEEE Access, vol. 6, pp. 15980-15996, 2018,

[35] A. M. Ahmed, T. Qiu, F. Xia, B. Jedari and S. Abolfazli, "Event- Based Mobile Social Networks: Services, Technologies, and Applications," IEEE Access, 2014, vol. 2, pp. 500-513.

[36] A. Alshamrani, S. Guha, S. Pisharody, A. Chowdhary and D. Huang, "Fault Tolerant Controller Placement in Distributed SDN Environments, " 2018 IEEE Inter- national Conference on Communications (ICC), Kansas City, MO, 2018, pp. 1-7.

[37] N. Mouawad, R. Naja and S. Tohme, "Optimal and Dynamic SDN Controller Placement," 2018 International Conference on Computer and Applications (ICCA), Beirut, 2018, pp. 1-9.

[38] E. Borcoci, T. Ambarus and M. Vochin, "Distributed control plane optimization in sdn-fog vanet", ICN 2017, pp. 135, 2017. Retrieved October 15,2020 .

[39] J. Lu, Z. Zhang, T. Hu, P. Yi and J. Lan, “A Survey of Controller Placement Problem in Software Defined Networking," IEEE Access, vol. 7, pp. 24290-24307, 2019.

[40] Y.-D. Lin, P.-C. Lin, C.-H. Yeh, Y.-C. Wang, and Y.-C. Lai, "An extended SDN architecture for network function virtualization with a case study on intrusion pre- vention," IEEE Netw., vol. 29, no. 3, pp. 48-53, May 2015.

[41] Rohit Das, Wanbanker Khongbuh, Fabiola Pohrmen, Arnab Maji, Goutam Saha, "Controller Placement and Selection strategy for SDN". 2. 473477. Retrieved October 12, 2020.

[42] V. Huang, G. Chen, Q. Fu and E. Wen, "Optimizing Controller Placement for Software Defined Networks," IFIP IEEE Symposium on Integrated Network and Service Management (IM), Arlin, 232, 2019.

[43] Tran, Anh Piran, Md Pham, Chuan. "SDN Controller Placement in IoT Networks: An Optimized Sub modularity-Based Approach". Sensors (Basel, $\quad$ Switzerland). 19. 10.3390/s19245474.

[44] A.K. Singh, S. Maurya, S. Srivastava, "Varnabased optimization: a novel method for capacitated controller placement problem in SDN". Front. Comput. Sci. 14, 143402 (2020).

[45] M F Bari, A R Roy, S R Chowdhury, Q Zhang, M F Zhani, $\mathrm{R}$ Ahmed, $\mathrm{R}$ Boutaba. "Dynamic controller provisioning in software defined networks. Proceedings of the 9th International Conference on Network and Service Management. 2013, 18-25.

[46] Y. Li, S. Guan, C. Zhang and W. Sun, "Parameter Optimization Model of Heuristic Algorithms for Controller Placement Problem in Large-Scale SDN," IEEE Access, vol. 8, pp. 151668151680, 2020.

[47] R. V. Rao, V. J. Savsani, and D. P. Vakharia, "Teaching-learning-based optimization: A novel method for constrained mechanical design optimization problems," Comput.- Aided Des., vol. 43, no. 3, pp. 303305, 2011.

[48] A.K. Singh and S. Srivastava, "Varna-based optimization: A new method for solving global optimization," Int. J. Intell. Syst. Appl., vol. 10, no. 12, pp. 1-15, Dec. 2018.

[49] Sahand Torkamani-Azar, Mohsen Jahanshahi, "A new GSO based method for SDN controller placement", Computer Communications, Volume 163, 2020, Pages 91-108.

[50] A. Ruiz-Rivera, K.-W. Chin, S. Soh, "GreCo: An energy Aware Controller Association Algorithm for Software defined networks", IEEE Commun. Lett. 19 (4) (2015) 541-544.

[51] A. A. Z. Ibrahim, F. Hashim, N. K. Noordin, A. Sali, K. Navaie and S. M. E. Fadul, "Heuristic Resource Allocation Algorithm for Controller Placement in Multi-Control 5G Based on SDN/NFV Architecture," IEEE Access, vol. 9, pp. 2602-2617, 2021.

[52] M. S. Kumar and J. Prabhu, "Analysis of network function virtualization and software defined virtualization," Int. J. Inform. Vis., vol. 1, no. 4, pp. 122126, 2017.

[53] S. Manzoor, Z. Chen, Y. Gao, X. Hei, andW. Cheng, "Towards QoS-aware load balancing for high 
density software defined Wi-Fi networks," IEEE Access, vol. 8, pp. 117623117638, 2020.

[54] M. S. Bonm, K. L. Dias, and S. F. L. Fernandes, "Integrated NFV/SDN architectures: A systematic literature review," ACM Comput. Survey, vol. 51, no. 6, pp. 139, 2019.

[55] A. Jalili, M. Keshtgari, and R. Akbari, "A new framework for reliable control placement in software defined networks based on multi-criteria clustering approach," Soft Comput., vol. 24, no. 4, pp. 28972916, Feb. 2020.

[56] G. Li, X. Wang, and Z. Zhang, "SDN-based load balancing scheme for multi- controller deployment," IEEE Access, vol. 7, pp. 3961239622, 2019.

[57] Rene Molenaar. "Introduction to SDN". Retrieved October 10, 2020.

[58] B. Nunes, M. Mendonca, X.-N. Nguyen, K. Obraczka, and T. Turletti, "A survey of softwaredefined networking: Past, present, future of programmable networks," IEEE Commun. Surv. Tut., vol. 16, no. 3, pp. 1617-1634, Third Quart. 2014.

[59] Wikipedia contributors. (2021, April 22). "Software-defined networking." Wikipedia, The Free Encyclopedia. Retrieved October 10, 2020.

[60] N. Cai, Y. Han, Y. Ben, W. An, and Z. Xu, "An effective load balanced controller placement approach in software defined WANs," Proc. MILCOM IEEE Mil. Commun. Conf. (MILCOM), Nov. 2019, pp. 361-366.

\section{Author Biography:}

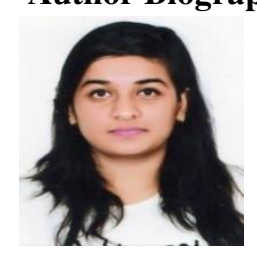

Lakshita Agarwal received the degree in Bachelors of Technology in Computer Science and Engineering, from College of Engineering Roorkee (COER), Roorkee, Uttarakhand, India, in the year 2019. Currently she is pursuing Maters of Technology in Computer Engineering from College of Technology, G. B. Pant University of Agriculture and Technology, Pantnagar, Uttarakhand, India. Her main research interest areas are in the field of Computer Networking and she is currently working on the Controller Placement Problem in the Software Defined Networks. (lakshitaa3@gmail.com)

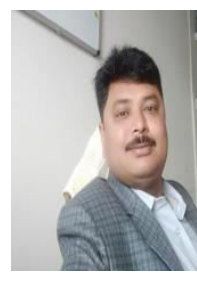

Chetan Singh Negi received his Bachelors of Technology (Computer Science and Engineering) from U.P. Technical University, Lucknow, India. He has done his Masters of Technology from IIT Kharagpur, India. He is pursuing his Ph.D. degree from Department of Information Technology, College of Technology, GBPUAT, Pantnagar, India. He is currently working as Assistant Professor in the Department of Computer Engineering, College of Technology, GBPUAT, Pantnagar, India. His research interest includes Image Processing, Software Defined Networking (SDN), and Service-Oriented Architecture. (csnegi.iitkgp@gmail.com)

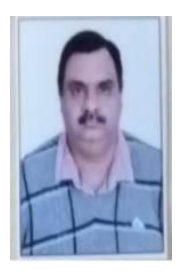

Jalaj Sharma received his Bachelors of Technology (Computer Engineering) and Master of Technology (Computer Engineering) from College of Technology, Pantnagar. $\mathrm{He}$ is currently working as Associate Professor in the Department of Computer Engineering, College of Technology, GBPUAT, Pantnagar, India. His research interest includes Microprocessor, Embedded Systems and Computer Networks. (jalajsharma.cse@gbpuat-tech.ac.in)

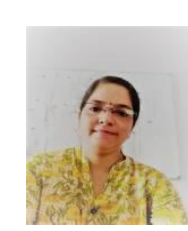

Sunita Jalal received her Bachelors of Technology (Computer Science and Engineering) from U.P. Technical University, Lucknow, India. She has done her Masters of Technology (Computer Science) from Banasthali Vidyapith, Rajasthan, India. She is pursuing her Ph.D. degree from MNNIT Allahabad, India. She is currently working as Assistant Professor in the Department of Computer Engineering, College of Technology, GBPUAT, Pantnagar, India. Her research interest includes Service Oriented Architecture, Web Service Discovery and Composition, Computer Networks, Machine Learning. (sunita.jalal@gmail.com). 